\title{
MAKING SENSE OF IT ALL: THE DEBATE AS UNIT CAPSTONE
}

\author{
Amanda Lea Miracle \\ Emporia State University
}

One of the challenges in teaching college-level surveys of United States history (and other basic courses as well) is the wide disparity in levels of college readiness among students. Not only do students vary in their skills of critical analysis, but they also differ in regards to their familiarity with the narrative of American history. To help students develop and practice their skills of analytic reasoning while at the same time reinforcing the covered material, I decided the best solution was to employ a series of debates in which each student, working with partners, takes a turn debating a major proposition in front of peers. I also assign a formal paper to be completed independently by each student debater. This is to ensure that before students square-off in front of the classroom they have clarified their reasoning and are prepared to explain how each of their main points proves their thesis. To assure that this is more than a passive exercise for those not engaged in the debate, the rest of the class sits as "jury," charged with evaluating their colleagues' use of evidence. At the end of the debate, these students raise questions to the student debaters in regards to how well the evidence actually proved the central point each side argued. Thus, I find the debate format quite useful as a capstone exercise to a unit because it encourages students to summarize the material covered to date, to create and justify an interpretation, and then allows for peer review and evaluation of the degree of successful critical reasoning. While I currently use this format in an eighty-minute class (and then follow the debate with a discussion activity), I also have employed this format in a fifty-minute period by shortening the amount of time the jury engages in discussion.

In teaching the United States history survey, I make a number of assumptions in trying to reach a variety of learners with differing degrees of familiarity with the historical narrative. This approach assumes that the instructor need not cover all of the material in class, delivering every name, date, event, etc. for which students are responsible. Assigned text and companion essay readings work in concert with classroom instruction. This approach allows time to incorporate the debate into classroom activities - actually to be the capstone of the unit's activities-without suffering the loss of content. At present, I divide the first half of the American survey into five units: Pre-Contact and Colonial America, Revolutionary America, The Market Revolution, Antebellum America, and Civil War and Reconstruction. Within these units I cover several topics in-depth to allow for closer examination of selected themes. At the end of the unit, as the summation of material, I assign a debate in which students revisit the sequence of events, themes, and topics to be able to evaluate a given proposition successfully.

This approach of using debate as a unit capstone is founded in brain-based learning methodology, specifically following the Highly Effective Teaching model 
developed by Susan Kovalik. Her approach "carefully develops a brain-compatible learning environment, then structures the curriculum to take advantage of the way the brain learns best." Kovalik's nine elements, which acknowledge the multiple intelligences of students while helping to create meaning, are as follows:

1. For learning to happen, the instructor must create an absence of threat and a nurturing environment.

2. Content must be meaningful. To this end the instructor should help students draw connections to their prior learning and help them feel connected to a community. ${ }^{2}$

3. The instructor must create an enriched environment through providing multisensory input.

4. Movement enhances learning. As students engage in activities that activate the brain on both sides, they avoid the process of lateralization. Simply stated, as more parts of the brain are engaged in active learning, the better the student will be able to remember.

5. Essential to creating meaning is choice. Students will be more invested when having ownership of their learning.

6. The instructor must establish a schedule that offers ample and flexible time for students to reflect on and internalize information.

7. Students need to collaborate to be able to work together to solve problems. ${ }^{3}$ According to Kovalik, "This leads toward career skills in communication and interaction for solving problems, exploring, and creating when learning or performing." ${ }^{4}$

8. Students need immediate feedback. Coaching is necessary to help motivate students and refine their work.

\footnotetext{
${ }^{1}$ Kathy Dorner, "Using Technology in a brain-Compatible Learning Environment," Educational Technology Training Center, http://ettc.lrhsd.org/archives/dorner.html (accessed January 31, 2012).

${ }^{2}$ Kathleen Cercone, "Brain-Based learning," in Enhancing Learning Through Technology, edited by Elsebeth Korsgaard Sorensen and Daithi O Murchu (Hershey, PA: Idea Group, Inc., 2006), 312.
}

${ }^{3}$ Tbid., 313.

${ }^{4}$ Susan J. Kovalik, "Nine Bodybrain-Compatible Elements of the HET Model," The Center for Effective Learning, http://www.thecenter4learning.com/html/resources/9elements.htm (accessed January 31, 2012). 
9. For meaning to occur, students need to internalize what they learn and demonstrate mastery through application. ${ }^{5}$

For the debate (or any activity in which students express their ideas) to facilitate participation effectively, the following is key: The instructor must create a classroom community in which students feel safe expressing their ideas. And, the debate (ideally) should be on a topic in which students have interest. This is why I allow students to select one of four or five debates at the beginning of the semester. As Kovalik's element five suggests, this helps to spark student interest and keep them motivated. When the topic is one they care about, students tend to make more of an effort.

\section{Pre-Debate}

In preparing for the debates, students re-articulate content covered from lectures, readings, films, and the variety of other classroom activities. This is consistent with Kovalik's element two. To engage successfully in this activity, students must command the entirety of the material. They must draw on their wealth of exposure to the material in order to make connections. For example, one cannot debate the degree to which the American Revolution was a true "revolution" without understanding its causes and outcomes. Moreover, students also must examine the revolution from a variety of positions-it is insufficient, for example, to examine the elite "founders" alone. Students additionally have to think across class, race, and gender lines to examine those left out. Then, the debate proposition requires students to apply this knowledge in a new (to them) way--they have to define what constitutes a "revolution" before they can evaluate the degree to which the American Revolution meets the definition. Is there enough real lasting change, for enough people, for example, to consider this a "thorough" event? By contrast, do we need to see change across all levels of society before a revolution can be fully declared? Or, can certain changes be so significant to outweigh shortcomings? The answers students offer is what helps this dialogue to become so rich.

Moreover, in preparing for the debates students also practice critical reading skills through a close analysis of assigned literature. For their class texts, I assign them to read two secondary-source authors with differing views on a given topic. Thus, students might read a selection on the American Revolution written from the perspective of an historian emphasizing the underclass and their experience in addition to a traditional top-down reading. In looking for material that will support their given position, students re-read these selections, looking beyond the sequence of events and now ask what these readings mean - both about the author (and his or her purpose and

${ }^{5}$ For a more complete explanation of Kovalik's nine elements and the neuroscience that supports them, see ibid. 
fairness in coverage) and about the past. By comparing authors, students begin to see that different writers, starting from different viewpoints and asking different questions, can reach different conclusions about the same event. They begin to see that perspective shapes how interpretation is made and understood. This is a helpful first step for students as it then helps them to choose their materials selectively and weigh evidence to support their positions.

Through the use of a primary document reader or additional documents made available through a medium such as Blackboard, students also are challenged to check the given claims of selected historians by first asking: "What do the primary documents suggest about the extent to which the American Revolution marked a radical shift in American history?" By examining the documents, they can evaluate for themselves whether or not a particular piece of evidence (such as in the creation of a modern democratic republic) is significant enough to counterweigh evidence that might suggest an alternative conclusion (such as the fact that most slaves did not share in this newfound freedom). Thus, this exercise helps students answer this question: "Do the documents support the claims of the authors-or do they lead me to an alternative interpretation?" A closer examination of the primary evidence used by secondary authors to arrive at their conclusions helps students analyze the historians' reasoning. In this way, students can practice refining their critical thinking skills, while preparing for the cross examination portion of the debate. If they understand why they disagree with the conclusions of the secondary historian, they are better prepared to answer the criticisms of the opposing debate team.

An examination of primary and secondary sources in combination with class lectures and activities enables students to begin to craft their own unique if limited interpretations. Consistent with Kovalik's element three, the diversity of these sources and resources helps to create an enriched environment as it targets a large array of ways students learn - doing group work, analyzing images, listening to films, discussing their ideas, and engaging in an interactive lecture, for some examples. Although all of the students on a given side argue the same position, such as "The American Revolution was not far reaching enough to be called a true revolution," each student is charged with the task of justifying this statement. In short, each one must finish the following statement individually: "The American Revolution was not sufficiently far reaching to be termed a true revolution because ...?" How students answer this question for themselves and articulate it to their peers is evidence of metacognition, higher-level reasoning, that will help long-term retention and the more immediate preparation for exams.

\section{During the Debate}

For the oral debate, each student debater's grade rests mainly on how well they explain their three supporting pieces of evidence and the degree to which they connect 
these points back to the larger thesis of their side ${ }^{6}$ However, as each student debater builds on the argument of other debaters in an effort to prove a thesis, the debate teams have to work together to prepare - even before the debate in the classroom actually takes place. This is consistent with Kovalik's element seven. In student meetings outside of the classroom, students help each other make connections. My teaching assistant facilitates one of these meetings, but many students find that they need additional time to strategize and brainstorm and so meet outside of our scheduled meeting. This is the best application of group work: Students explain concepts to teammates, help them brainstorm ideas, and make connections. Consistent with Kovalik's element one, the group setting also helps to reduce student anxiety during the debate. They have other students to help them clarify ideas during cross-examination. Students also help each other refine basic skills of college success. For example, students often compare their notes from the reading. Doing so allows students to see what they might have missed but others did not. This comparison helps them to refine their critical reading skills. That each student's grade rests mainly on what they argue helps to alleviate the worst application of group work and a great deal of student frustration: That some students can coast by allowing other students to do the work for them.

The debate format also creates a forum in which each student expresses his or her own individual interpretation. So often students simply repeat ideas offered by the instructor without ever stopping to evaluate material for themselves. This activity requires all students, each student in turn, at least once, to explain what they think and why. And, in so doing, perhaps they begin to understand what we mean when we say at the beginning of each semester that "What you think matters in this room. History is more than just a regurgitation of facts and events. Your interpretation of those events, facts, and themes--grounded on evidence-is what matters." One of my key goals in the survey is to encourage students to think.

For students who do not engage in the debate as participants arguing in defense of either side, these students (as the jury) also benefit from listening actively during the debate and then vocally participating at the end. As debaters again cover the material, they reinforce to the jury material already presented. Their dialogue also challenges the jury to consider the application of a new proposition. More than simply listening to a re-hash of common-knowledge information, the jury is charged with evaluating the degree to which both sides of the debate have proven their respective positions. They do this in both written form, when they complete their analysis sheets, and in oral form at the end when the jury raises questions and comments. It is the participation of the jury that makes the debate format so valuable. The jury evaluates the critical reasoning and evidentiary justifications of individual debaters. And, the jury tends to be quick to

\footnotetext{
${ }^{6}$ The author is happy to share her associated debate documents: "Instructions to Debaters," "Sequence," "Rubrics," and "Jury Page." Please contact amiracle @emporia.edu for copies.
} 
point out when the jury fails to connect one of the supporting points to the larger thesis. By the same token, they offer praise to individuals who support their ideas with clear reasoning and concrete examples as supported with class readings. Consistent with Kovalik's eighth element, the debates foster immediate feedback to the student presenters through the jury.

The feedback offered at the end and the lively discussion that ensues between debaters and members of the jury distinguish a debate from the sort of critical analysis offered in a traditional paper or exam format. In a traditional paper or exam, students generally submit their analysis and then read whatever comments the instructor writes. Usually the dialogue ends here. But in the debate format the jury will continue to question debate members until the idea is sharpened and fully explained. Thus the process of explaining an idea and supporting it with evidence-the essence of critical thinking - can be refined until the connection between how a given point proves a particular thesis is clear. To members of the debate, hearing their peers make observations and offer explanations on how connections might be made differently seems to matter a great deal. By working together debate members and jury members seem to arrive jointly at "Ah-ha" moments. And thinking is born.

\section{Post-Debate}

To help monitor student progress in critical thinking, I use a variety of assessment tools to help inform the feedback I offer to students in our post-debate meeting. After every debate, I hold an extra-credit one-on-one meeting with students to address their strengths and weaknesses in critical thinking and writing. My first method of assessment follows the oral portion of the debate. At the beginning of a debate, each student debater distributes copies of his or her handout; the jury, their team members, the opposing team members, and I all receive a copy. The handout explains the points the student plans to raise and provides the logical reasoning for how their points proves their thesis. Having downloaded the debate rubric from Blackboard prior to the beginning of class, students hand me a copy of their handout with the rubric attached. I use this document to help monitor how well students explain their ideas and the reasoning behind them. While some of their grade is based on traditional oral presentation criteria, such as eye contact and elocution, far more rests on how well they grasp the information and use it to support their thesis.

Specifically, I look for the following factors:

1. Do the points, in fact, connect to the thesis? And, does the thesis accurately respond to the prompt?

2. How well do students explain their points and respond to counterpoints?

3. How well do students explain their evidentiary support?

4. To what degree do students make the last step and use the evidence to prove their point while showing connectivity to the larger argument? 
The second method I use to monitor student progress is the formal written essay that students submit on the day of the debate. However, whereas in the oral portion of the debate I mostly check for content and reasoning, in the written essay I also monitor elements of good writing. Before coming to class students download a "Debate paper" rubric from Blackboard, which they attach to their papers. For students who do not take advantage of the extra-credit meeting, they doubly benefit from the rubrics as I offer them an abridged version of my comments on these forms.

My informal check to ensure that students are making steady progress in their critical reasoning skills comes through observation of completed jury sheets. On these sheets, students reflect on the arguments of peers and their use of evidence. As the semester progresses, students become more adept at pointing out both the flaws and strengths in the arguments of classmates. Another informal check I use, albeit after the semester has closed, is in student responses. These suggest that while students might find this activity difficult, it seems to have the desired effect of making them think. On my student evaluations, student comments regarding debates span the gamut from wild enthusiasm to loathing - depending on how students feel about having to think. Some recent comments include "Very difficult but made me think ..." or "The debate was a little overwhelming but good to have" and "This is only a 100-level class. I am a senior taking 600-level classes and this was my most challenging class."

The last method I use to monitor student development is to analyze the numeric scores of their other critical thinking assignments. In the survey, I have students write a total of five short essays (250-500 words). Like the debates, these short essays ask students to consider assigned reading and then create and support a thesis by taking a position in response to a focused question. All students must complete the first essay on the same day. Generally, I assign this essay within the first three weeks of class, before any of the debates. Students have considerable choice of when to submit their other essays as I allow fifteen possibilities distributed throughout the semester. They may submit four of the short essays whenever they choose, so long as it is on one of the allotted days. Many students, for example, submit these short essays on debate days. While the debate is an excellent capstone to the unit, critical thinking is an ongoing process - of which the debate is a part. Thus comparing the student scores of their first short essay with their last submission provides a good gauge of how their skills seem to improve. In general, these scores suggest marked student improvement overall — for some students by as much as twelve to fifteen percent. 